\title{
INTESTINAL EXTRACT IN RHEUMATIC DISEASES
}

\author{
BY \\ ARNOLD RENSHAW \\ Manchester
}

Many theories, ranging from familial and climatic factors to specific focal infection, have been advanced_from time to time to explain the aetiology of rheumatic diseases. None of these theories are, however, supported by incontestable data. Much attention has been given to defects and disease in the stomach, the gall-bladder, and the colon; but the functions of the small intestine have received little notice and less research.

As a result of numerous post-mortem examinations, sometimes as many as four or six a day for many years, the frequency with which atrophy of the small intestine occurred and the variations in the appearance of this organ when it was systematically opened and examined throughout its entire length impressed itself upon the writer. The conclusion was reached that rheumatoid arthritis might be a deficiency disease, with perhaps some associated allergic basis, and that the deficiency might arise from an inability to deal adequately with protein digestion and metabolism. It is to be noted that the area of the small intestine, excluding folds and villi, is at least nine or ten times that of the stomach, and Martin and Banks of McGill University (1940) showed that the weight of the dried intestinal mucosa is from three to five times that of the dried pancreas.

A special research was, therefore, instituted into the condition of the small intestine in rheumatic patients. It was difficult, especially during the war, to obtain post-mortem material from suitable cases, but a few typical cases were met with and histological material was also obtained from time to time by the kind help of Dr. R. Y. Dawbarn of Liverpool. Some of the material was the outcome of sudden death (cerebral haemorrhage, etc.) and was obtained within twenty-four hours of death-the external temperature being low or the bodies stored in ice chambers; but some specimens were only available two, three, or even in one case four days after death. Comparison has, however, been made histologically between these cases and that of animal intestines kept for a week after death which presented less severe changes. There is no doubt at all in the mind of the writer that the changes found represent a true disease process and are not autolytic. Some autolysis is, of course, possible; but changes such as fibrosis and endarteritis can by no means be regarded as such, nor can the denudation of the mucosa in large areas when the 
nature of the underlying stroma is considered; in cases of Paget's disease the intestine shows a hypoplasia almost incredible in degree.

Sections of the small intestine were made at three levels: (a) 6 in. below the pylorus; (b) half way along the small intestine; (c) 6 in. above the ileo-caecal valve. Essentially the changes met with vary in degree according to the severity of the disease. Thus, patients showing moderate bone changes of rheumatic type may show less severe damage to the intestinal mucosa than is present in advanced cases. In the former the chief changes appear to occur in the lower part of the intestine $(b$, or $c)$ whereas in the advanced cases all areas $(a, b$, and $c)$ are affected. The amount of mucosal damage is also greater in the advanced and wasted rheumatoid cases. Thus Fig. 7, from a case of this type, shows complete denudation of the mucosa in places, with considerable disorganization of the glandular acini and an increase of interglandular material which is shown by van Gieson's stain to be due to a fine inter-acinar fibrosis, the acini presenting the appearance of being further separated from each other than is normally the case, and many acini (Figs. 8 and 9, p. 26) are completely disorganized, with an appearance of hyaline degeneration.

The blood supply in the normal intestine in both children and adults appears to be far richer than in the intestine of rheumatic patients. The latter frequently shows an advanced degree of endarteritis, which, by limiting the blood supply, must inevitably reduce the amount which that tissue receives and can convert into secretion. (For various changes see Figs. 1-11, pp. 22-26.)

\section{Causes of Diminished Secretion}

Mucosal degeneration and deficiency of secretion may be due to a variety of causes, chief of which are: improper or inadequate diet, including absence of certain vitamins; chemical poisons or intoxications, including lead and alcohol (Bray, 1937; quoted in Brit. med. J., 1946); bacterial infections and toxins, including old tuberculous enteritis; and congenital tendencies leading to hypoplasia. Deficiency of secretion may be induced by mental or nervous disorders, shock, anxiety, etc.

It is known that food in the intestine stimulates the production of the succus entericus, and it is, therefore, probable that deprivation of the type of food which requires this secretion for its digestion would tend to produce disuse atrophy of the intestinal mucosa, and this has recently been confirmed by Magee (1945). $\mathrm{He}$ states that Sun, whilst working in his laboratory, drew attention to work which he had previously done (1927) on the effect of fasting on the epithelium of the gastro-intestinal tract. Sun showed that fasts of twenty-four hours or more caused progressive degeneration of the columnar cells of the intestine of white mice. After relatively long periods of fasting, all except the basal portion of the villi became disorganized and degenerated, and in extreme càses practically no trace of columnar epithelium or villi remained. Provided degeneration had not gone too far careful refeeding caused rapid regeneration. Magee also states that changes of the same type are referred to by Jackson (1925) and states that these findings 
indicate that deprivation of food progressively destroys the digestive, absorptive, and protective functions of the alimentary canal, and also it would seem to impair the metabolic functions.

\section{Experimental Method}

In view of these observations it was decided to test the effect of extract of intestinal mucosa in the treatment of patients suffering from rheumatism of various types, and for this purpose a firm of enzyme specialists agreed to prepare an extract of intestinal mucosa rich in erepsin and to use the resources of their laboratories for the necessary tests. The resulting product was presented in enteric-coated capsules for oral administration; these were designed to release their contents one hour after being swallowed. Since the hydrochloric acid of the gastric juice would inactivate the enzymes, an interval of two and a half hours after food seemed to be the optimum time for administration; this would allow the intact capsule to pass into the duodenum, there to dissolve and liberate its contents for subsequent action in an alkaline medium. Before the extract was administered to human beings, preliminary animal feeding experiments failed to show any evidence of toxicity. Later, inoculation experiments with a sterile extract were performed on animals before a parenteral method of administration was tested.

Treatment of patients with this extract have now been proceeding for seven years. Most types of rheumatic disease have been treated-rheumatoid arthritis, osteo-arthritis, fibrositis, synovitis, intermittent hydrarthrosis, acute and subacute rheumatism, and.spondylitis. Patients under ten years of age and over eighty have received treatment. In some the illness was of recent duration; in others there was a history of twenty-five years or more. Among over 700 cases treated by the writer personally, good results have been obtained in rheumatoid arthritis, osteo-arthritis, and fibrositis. Some intractable cases of ankylosing spondylitis and Still's disease have also responded to this therapy. The treatment has been carried out at a clinic at Ancoats Hospital, Manchester, and in private practice, and the results have been observed by many. physicians and general practitioners. Criteria for diagnosis and classification of results were drawn up with the assistance of physicians specializing in rheumatic diseases.

\section{Results}

In a series of 556 cases of various types, 283 were found to be much improved, and a further 219 were improved to a less marked extent. Of 292 cases of rheumatoid arthritis, 264 showed improvement of various degrees. Improvement was also noted in other forms of rheumatism. Children with Still's disease responded very well in the few cases treated, and relief of pain was frequently reported by patients with osteo-arthritis.

\section{Controls}

Some patients after treatment with an active extract have been given inactivated capsules without their knowledge. After three or four months of this the condition was noticed to deteriorate, to improve again when the genuine capsules were resumed-again without the patients being informed that a change of capsule had occurred. Other cases have relapsed on discontinuance of treatment after initial improvement, to improve again when intestinal extract treatment was resumed. Further controls have been afforded by the adoption of this treatment by patients 
who had relapsed after other methods but who improved with this method. Many cases had previously been treated with vaccines, gold, and other measures.

The technique which has been found to be the most effective, case reports, and statistics cannot be included in this paper for want of space, but will be the subject of a later report. Ancillary treatment has been avoided as far as possible as being likely to vitiate the conclusions to be drawn as to the effect of the method under consideration. A maintenance dose appears to be necessary for long after the disease has appeared to show any sign of activity. This compares with pernicious anaemia, diabetes, hypothyroidism, etc., and supports the theory that many forms of rheumatism are due to some systemic deficiency.

\section{CASE REPORT}

One case may be described, as it illustrates many points in the treatment, and was examined both before and after a long course of treatment, by independent observers.

A male, aged 36, occupation compositor, showed the first signs of rheumatoid arthritis in 1939 but was accepted for the R.A.F. in 1941; the disease became more active and he was in hospital for six weeks and was subsequently discharged. The joints affected were the hands, wrists, elbows, knees, and feet. When he came to the clinic he had to be brought by ambulance and carried in; he could dress himself, but could walk only very little and on some days was much worse than others. Treatment by the intestinal extract was begun on Feb. 10, 1943, and for the first two or three months there was little change; in fact he was if anything slightly worse in regard to generalized pain but the swelling of the joints was lessening and the range of movement was increasing. By the beginning of June he was able to walk with assistance, he was more cheerful, looked better, and his colour was improving. A few weeks later he was able to walk a mile and a half, but swelling of the ankles, and occasionally of the knees also, still occurred from time to time, up to November, when the dose of the extract was increased to 42 units (seven capsules) daily. By March, 1944, he could ride his bicycle, and soon was doing so on most days. In May his condition was reviewed by a Medical Board, as he had been in receipt of a pension from the Ministry, part of which was to defray the cost of his treatment. He continued to improve; the pain in the feet was relieved to some extent by metatarsal bars, and in November, 1944, he resumed his work as a compositor. In March, 1945, a Medical Board found him so much better that his pension was withdrawn. His weight improved from $6 \mathrm{st} .5 \mathrm{lb}$. at the beginning of treatment to $7 \mathrm{st} .12 \mathrm{lb}$. in January, 1944. When last examined, in October, 1945, he was still working and on his feet all day.

\section{Sedimentation Rate}

In all cases the sedimentation rate was regularly tested. Some patients showed rapid improvement in this respect; in others progress was slower and it took eighteen months or two years for the sedimentation rate to approach normal; while in some, in spite of marked clinical improvement, very little change in the rate took place. Blood-sugar tests were also carried out, and more recently attention has been given to the plasma proteins and the albumin-globulin ratio. It was found that overdosage tended to reduce the blood sugar and to produce mild symptoms of hypoglycaemia, which were readily corrected by diet: sometimes the addition of diastase corrected this tendency by improving the starch digestion. No other untoward reactions of any moment have been observed. 


\section{Discussion}

The beneficial effects observed as a result of the administration of the intestinal extract in rheumatic conditions differing in aetiology and pathology, such as rheumatoid and osteo-arthritis, would appear to indicate a common factor underlying all, and to support the idea, which was generally accepted by earlier workers in this field, of a rheumatic diathesis. This rheumatic diathesis may perhaps be defined as a constitutional state of the tissues, inherited or perhaps acquired, as a result of which such tissues are more vulnerable to the action of toxins, bacterial invasion, or trauma, and the ill effects of which are further aggravated by defects in intestinal digestion and assimilation.

Alteration in the relative proportions of certain protein molecules in the blood serum is a feature of rheumatoid arthritis and is met with also in some cases of osteo-arthritis. The normal ratio of albumin to globulin is about $4: 1$, the globulin molecules being about twice the size of the albumin molecules. In rheumatoid arthritis this ratio is altered to $2: 1,1: 1$, or even $0.75: 1$, which is assumed to be due to some breaking down of tissue to a greater degree than normal, to more globulin molecules being absorbed into the blood stream from the gut, or to absence of the normal mechanism, an enzyme or some unknown factor which may break down these large globulin molecules into the smaller albumin molecules. Whether this change in the blood proteins is a stage in the development of the disease or a result of the disease is at present a matter of speculation. It is known that erepsin is present normally in the blood, the kidneys, and other tissues, and that it is absorbed from the site of manufacture, the wall of the intestine, small or large; and the theory is submitted that this enzyme in the blood is a factor in the maintenance of a balanced proportion of proteins. Space will not permit of an elaboration of this hypothesis, although a considerable amount of experimental evidence is available and it was partly with this in view that the treatment was adopted. The presence of an undue proportion of the large globulin molecules alters the rate of dialysis of plasma through certain membranes, such as the ciliary fringes of the synovial membranes ; and investigation of the synovial fluid from this aspect is a matter worthy of further research.

The part played by allergy in some rheumatic diseases deserves consideration in the problem of the possible mode of action of this method of treatment. It has been held that the insidious and slowly developing processes of chronic rheumatism may be due to the continued influx of incompletely digested protein fragments into the blood stream, which act as antigens against which the antibody content of the circulating blood is low. The antigen-antibody reaction takes place within the cells with subsequent anaphylactic inflammation, the condition being described as allergic. The theory of protein allergy has the support of many workers in this field, one of whom, Gudzent (1940), was able to produce rheumatic tissue lesions in animals by various types of proteins, and observations on patients indicated that food proteins (animal as well as vegetable) are chiefly responsible. They produce 
under certain conditions antibody-antigen or allergic reactions, with their cytotoxic effects on the connective tissues, and thus lead to rheumatic tissue lesions.

All these suggested explanations of the mode of action of intestinal extract may be wrong, in part or entirely, but the fact remains that the application of the treatment in practice has given ample proof of its efficacy in a very large number of patients. Thus, no one to-day doubts the value of the Wassermann reaction, although its original premises were quite different; and no one denies the efficacy of liver or stomach extract in pernicious anaemia because the mode of action is still largely unknown. It is scarcely reasonable to expect that administration of an organ extract would have an effect upon a disease unless it stands in some relationship to the cause of that disease. The same argument may, therefore, apply if the symptoms of rheumatic disorder are alleviated markedly by the administration of an intestinal extract. If it does not stand in any aetiological relationship it is difficult to see how administration could possibly produce any improvement. After seven years' intensive application of this therapy, the writer has met with numerous instances in which its application has yielded as typical a response as could be desired. The nature of bone change is, however, so variable in the different cases presented for treatment that, however much the disease may be arrested, anatomical conditions alone prevent a return to normal in many instances. The importance of assessing the relationship lies in the possibility of preventing the devastating changes in the young and middle-aged with relatively slight risk to the sufferer.

\section{Some Points in the Treatment}

As would be expected, the longer the duration of the disease the longer will be the "lag" before improvement is observed. A patient who has had rheumatoid arthritis for only three months or so will usually begin to improve within about two months; three months may be regarded as the minimum period for the average case of two to five years' duration, whilst those with a disease of longer duration may require to be treated for six or twelve months before improvement in the rheumatic condition becomes obvious. Nevertheless if treatment is persistently maintained this class of case will show definite response in due course. The general health of the patient improves often beyond all recognition, weight is gained, and constipation, so common in these cases, often disappears; and these effects often precede improvement in the purely rheumatic symptoms. A maintenance dose is often required for years after the disease has apparently died out. The same holds good in most other conditions of deficiency, e.g. pernicious anaemia, diabetes, and hypothyroidism. Clinical evidences of this have been met with frequently in patients who have relapsed on stopping treatment and who have improved again when the intestinal extract was resumed.

It is important to maintain an adequate protein intake in the diet, and this should be spread as evenly as possible over the three main meals of the day. A high protein diet is complementary to intestinal extract treatment. Attention to 
carbohydrate digestion is important. Purgatives should be avoided as far as possible. Blood-sugar estimations should be carried out regularly, and symptoms of hypoglycaemia watched for and treated by dietetic measures, and by alteration of the dose of intestinal extract.

\section{Summary}

1. A large series of post-mortem examinations have shown atrophy of the small intestine to be marked in patients with rheumatic disease.

2. The effect of administration of an extract of small intestine mucosa is described, the mode of action discussed, and certain conclusions submitted to the effect that dysfunction of the secretory activity of the small intestine is an important factor in the aetiology of rheumatoid arthritis and allied conditions.

The writer wishes especially to acknowledge with sincere thanks the great help given by Dr. Reginald Ellis, F.R.C.P., Dr. C. W. Buckley, F.R.C.P., the laboratory and radiological staffs concerned-Mr. B. D. Thornley, B.Sc., and Mrs. Thornley, B.Sc., in particular-and also the Regional Officers of the Ministry of Health for much help regarding extension of laboratory facilities during war time.

\section{REFERENCES}

Bray, G. W. (1937). "Recent Advances in Allergy." London. Quoted in Brit. med. J., $1946,1,594$.

Clark, A. J. (1921). J. Pharm. exp. Therap., 16, 415.

Cori, C. F., and Goltz, H. L. (1925). Proc. Soc. exp. Biol., N.Y., 23, 122.

Gudzent. F. (1940). Med. Welt, 14, 545.

Jackson, C. M. (1925). " "The Effects of Inanition and Malnutrition upon Growth and Structure." Philadelphia.

Laughton, N. B., and Macallum, A. Bruce (1930). Canad. med. Assoc. J., 3, 348.

Looney, J. M., and Walsh, A. I. (1939). J. Biol. Chem., 130, 635.

Magee, H. E. (1945). Proc. roy. Soc. Med., 38, 389.

Martin, C. P., and Banks, J. (1940). J. Anat., 75, 135.

Putnam, T. J. (1923). Amer. J. Physiol., 63, 548.

Starling, E. H. (1909). " "Fluids of the Body ", p. 49. London.

Sun, T. P. (1927). Anat. Rec., 34, 341.

(For Illustrations to this Article see following pages) 

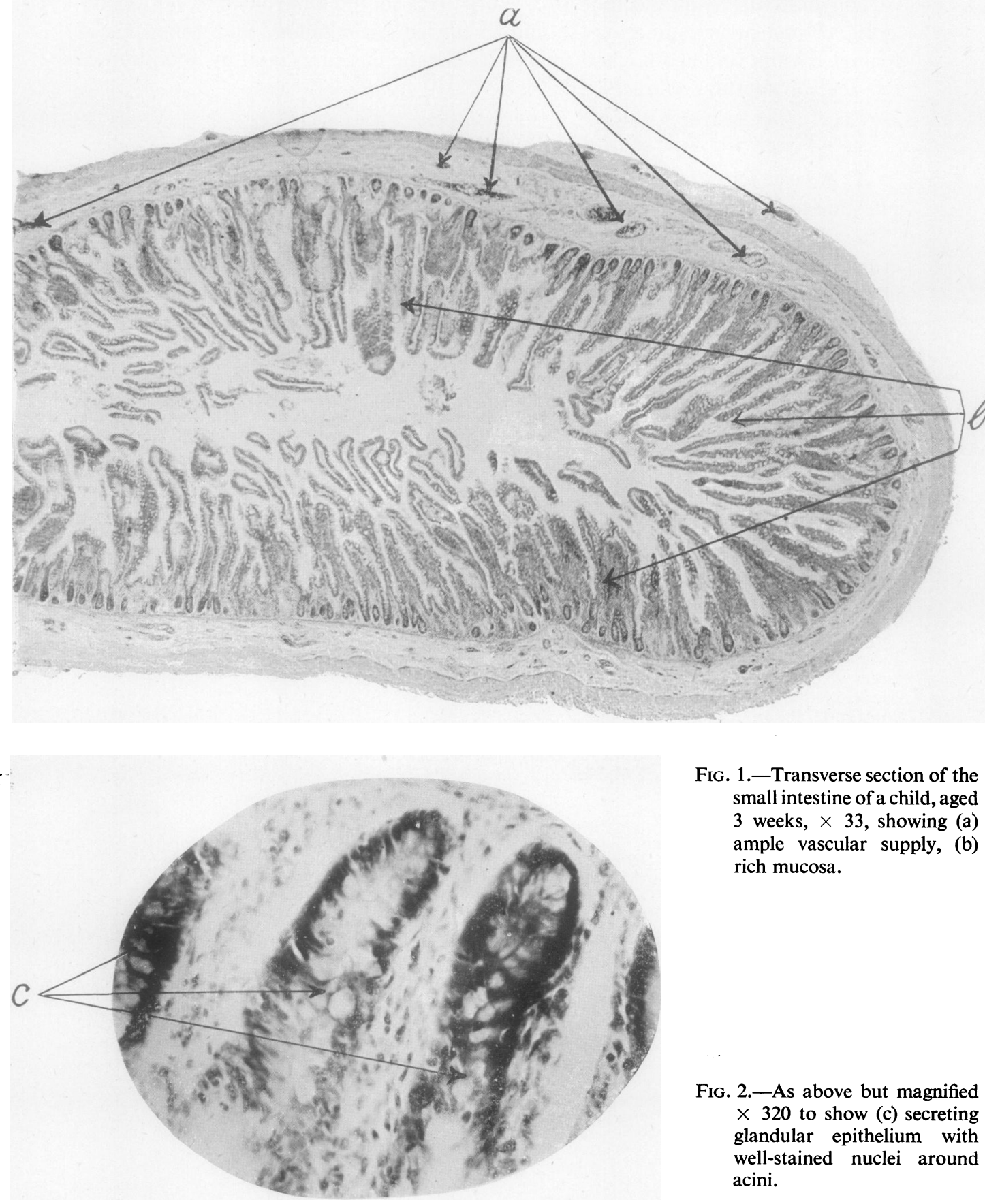

Fig. 1.-Transverse section of the small intestine of a child, aged 3 weeks, $\times 33$, showing (a) ample vascular supply, (b) rich mucosa.

b)

Fig. 2.-As above but magnified $\times 320$ to show (c) secreting glandular epithelium with well-stained nuclei around acini. 

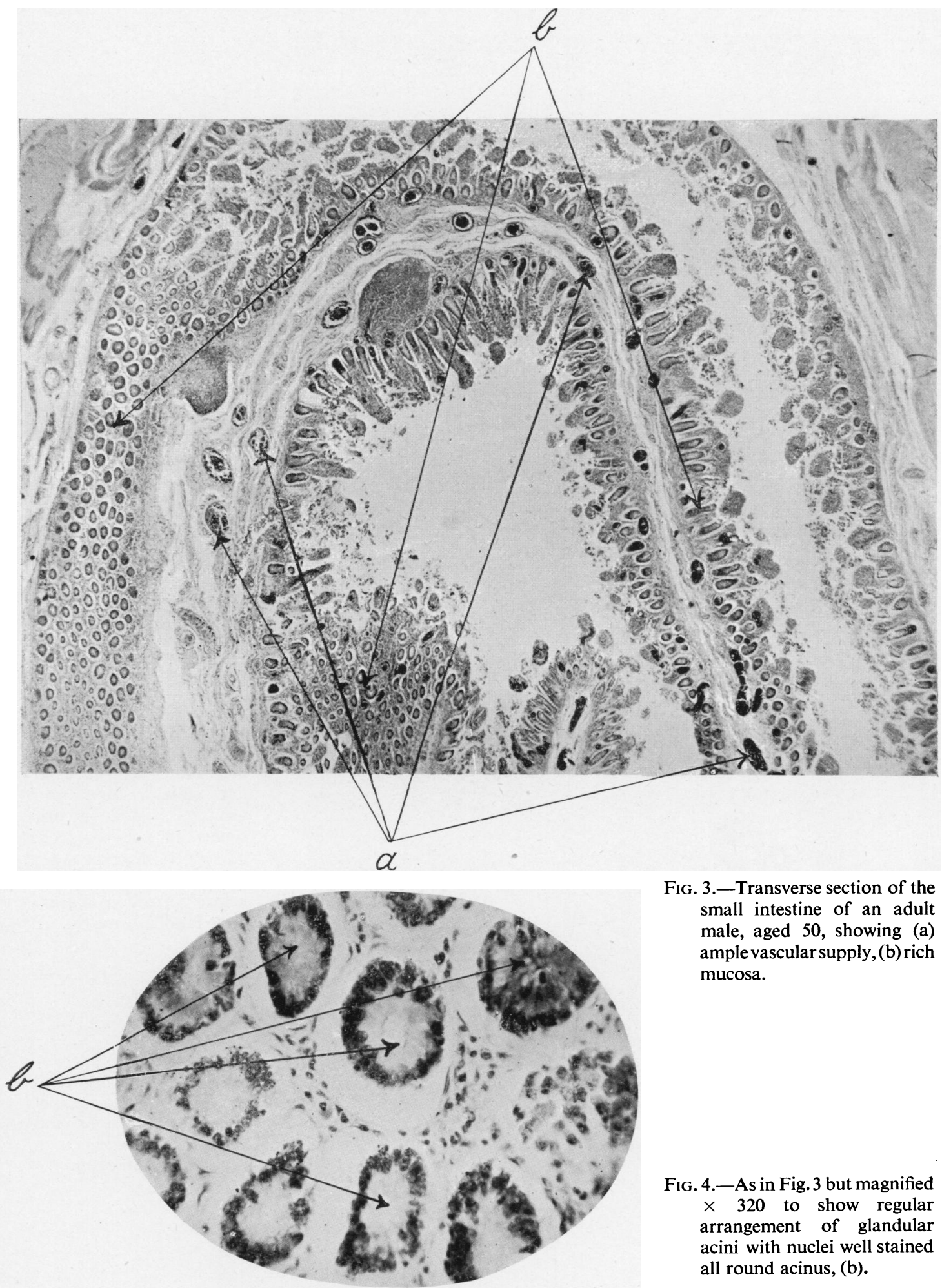

Fig. 3.-Transverse section of the small intestine of an adult male, aged 50, showing (a) ample vascular supply,(b) rich mucosa.

FIG. 4.-As in Fig. 3 but magnified $\times 320$ to show regular arrangement of glandular acini with nuclei well stained all round acinus, (b). 

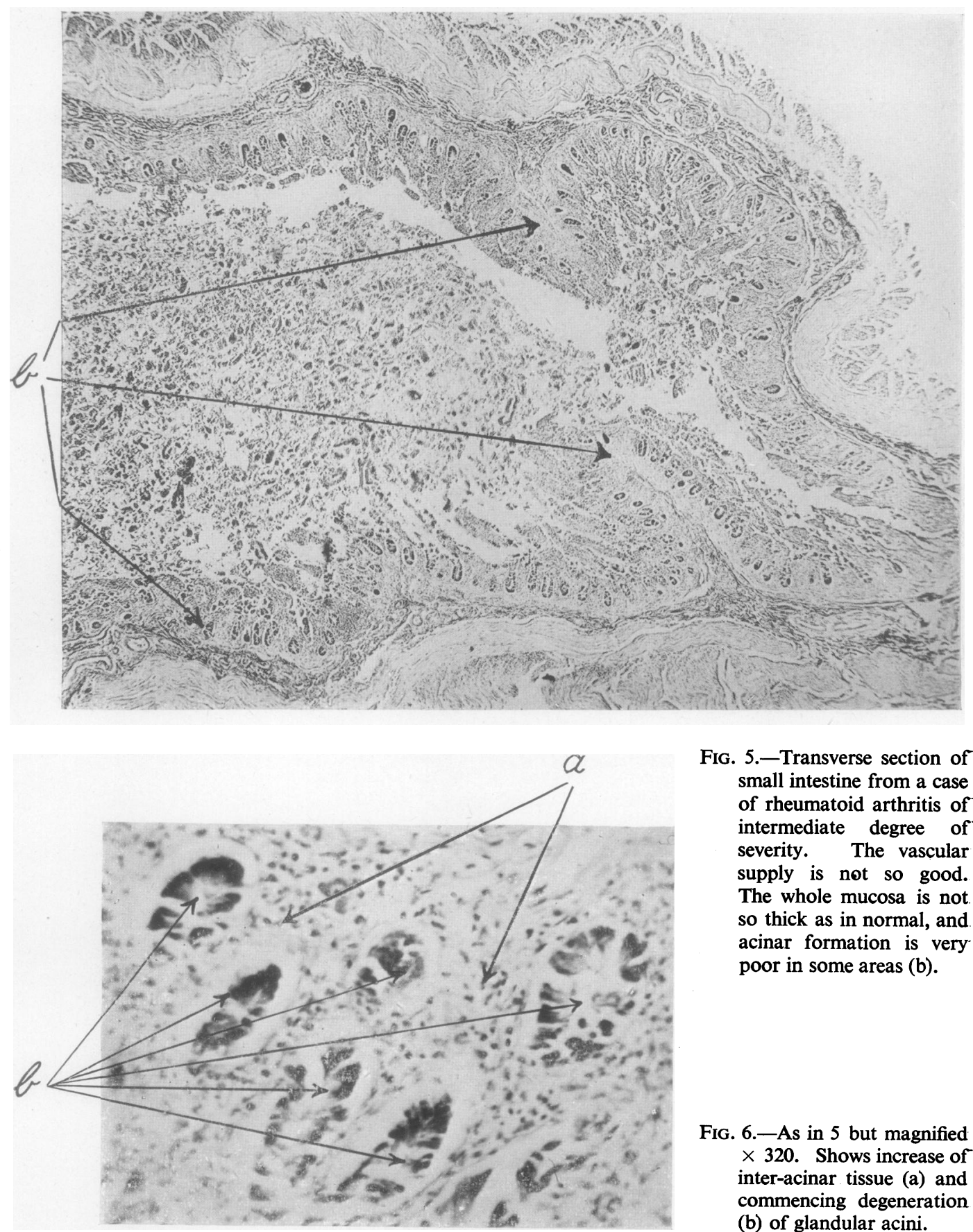

Fig. 5.-Transverse section of small intestine from a case of rheumatoid arthritis of intermediate degree of severity. The vascular supply is not so good. The whole mucosa is not so thick as in normal, and acinar formation is very poor in some areas (b).

Fig. 6.-As in 5 but magnified $\times 320$. Shows increase of inter-acinar tissue (a) and commencing degeneration (b) of glandular acini. 


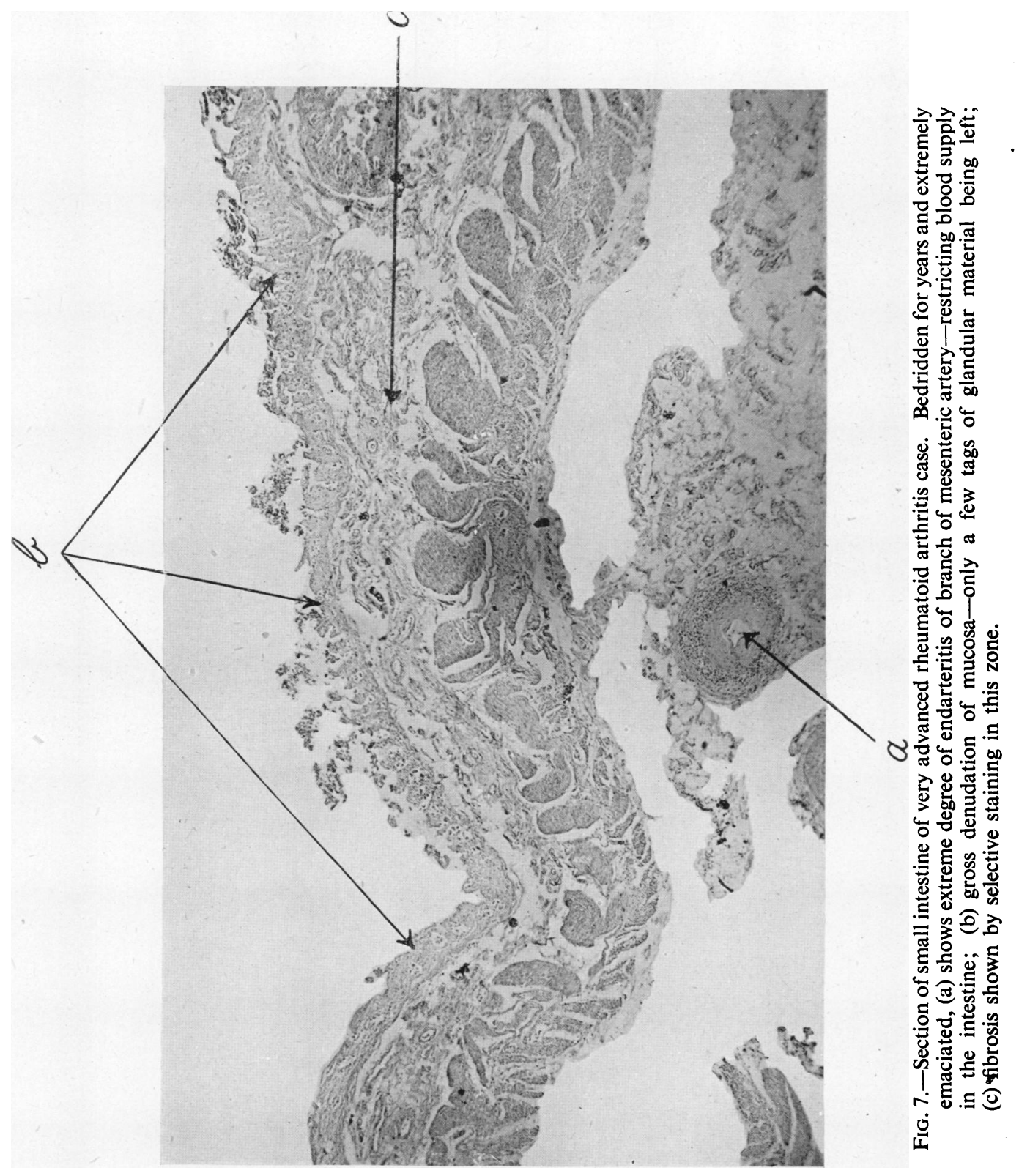



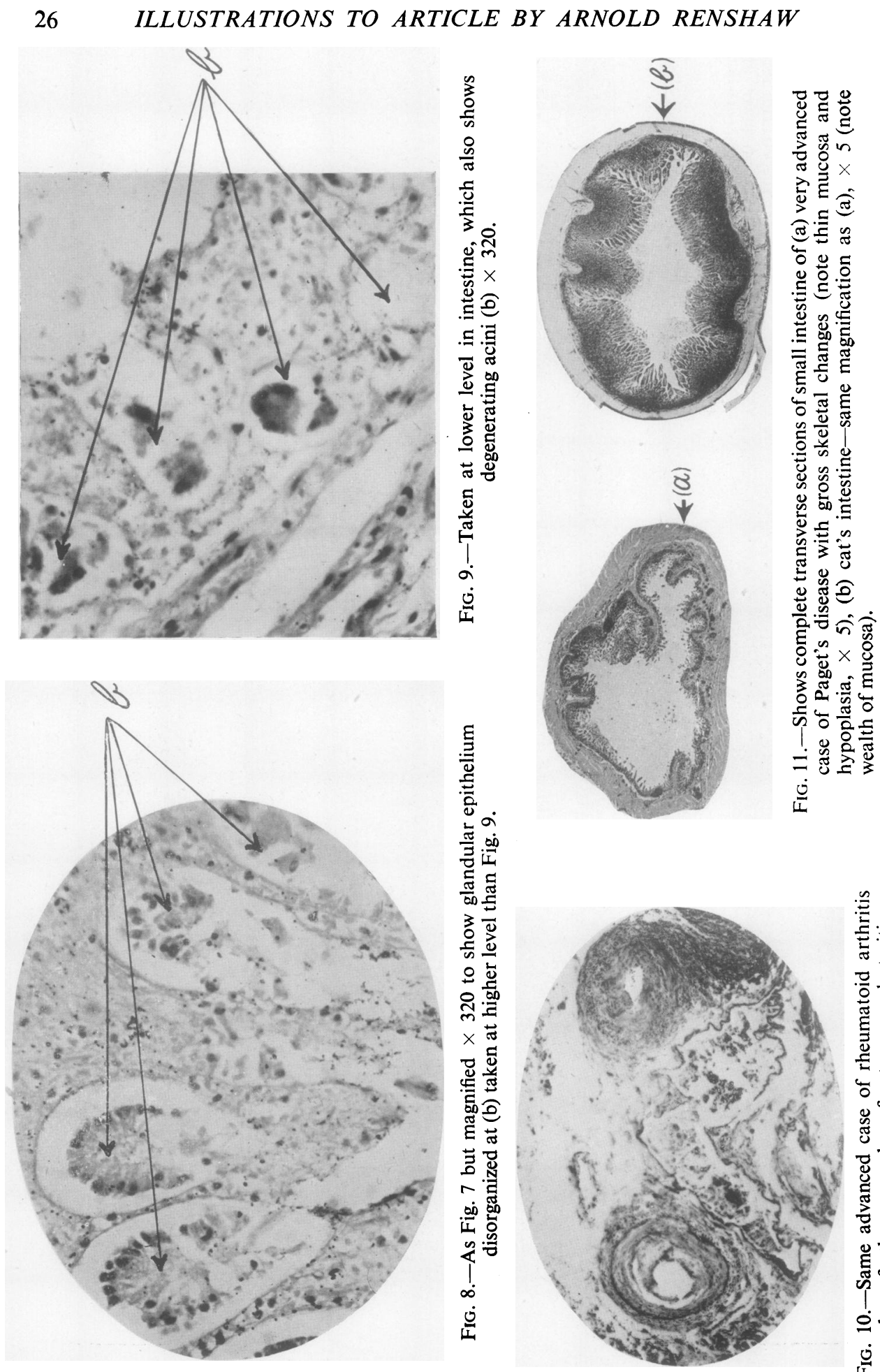

cे

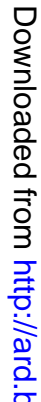

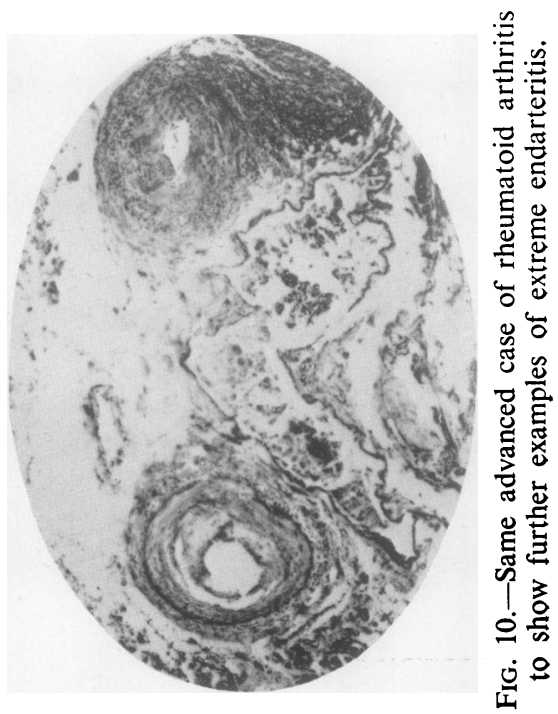



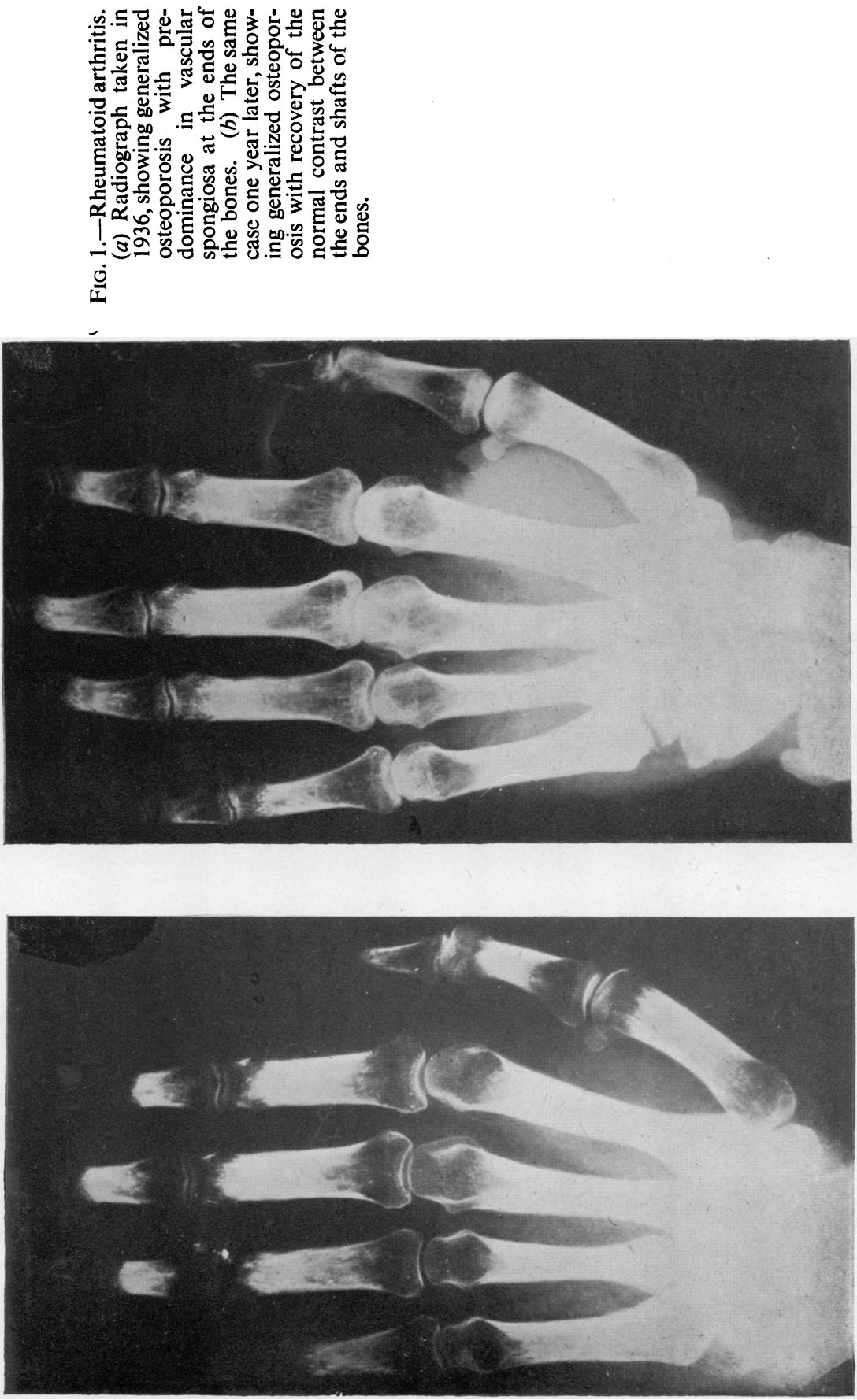


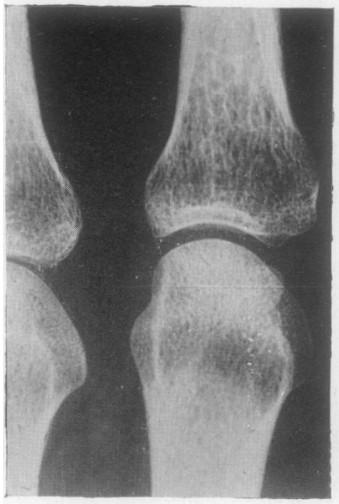

(a)

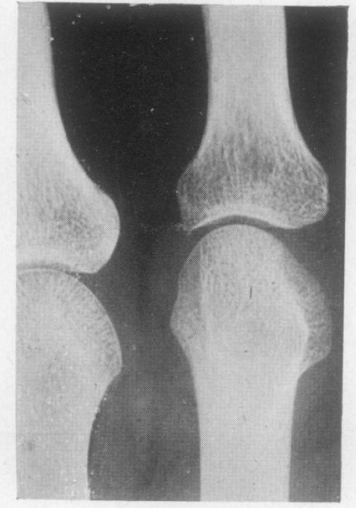

(b)

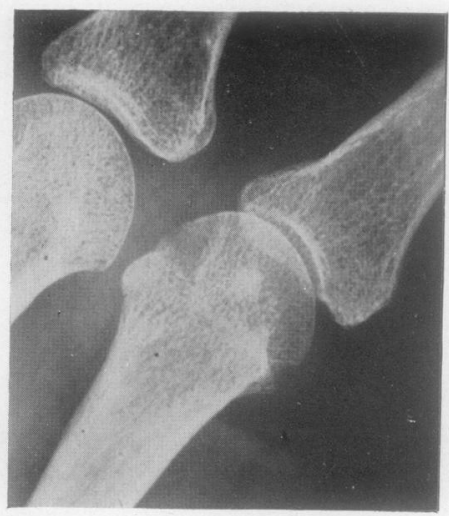

(c)

FIG. 2.-Examples of active changes of rheumatoid type from standard radiographs of the hands. (a) Generalized osteoporosis with a local pattern in the more vascular areas. (Corrected suspension stability $65 \%$; blood uric acid $3.8 \mathrm{mg}$. per $100 \mathrm{c.cm}$. of blood ; history, one year.) (b) Local osteoporosis of articular cortex due to subchondral invasion by granulation tissue. (c) Erosion at an articular margin, showing a local osteoporosis of the eroded trabeculae and of the adjacent articular cortex. (Corrected suspension stability $59 \%$; plasma uric acid $5.7 \mathrm{mg}$. per $100 \mathrm{c.cm}$. of blood ; history, two years.) An oblique projection was required to show this erosion in profile.

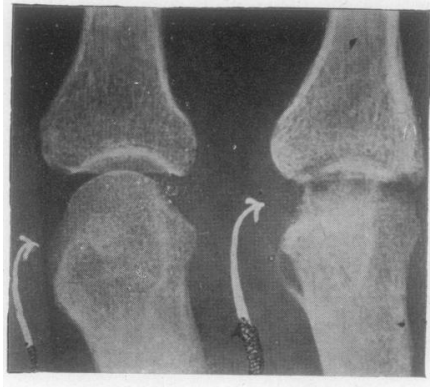

(a)

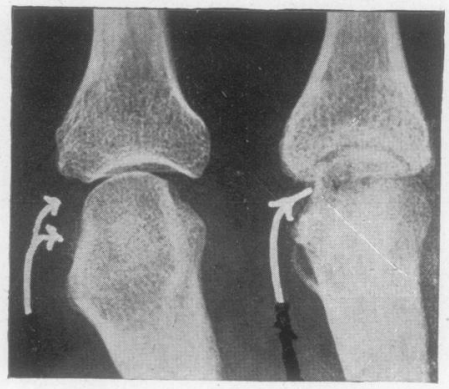

(b)

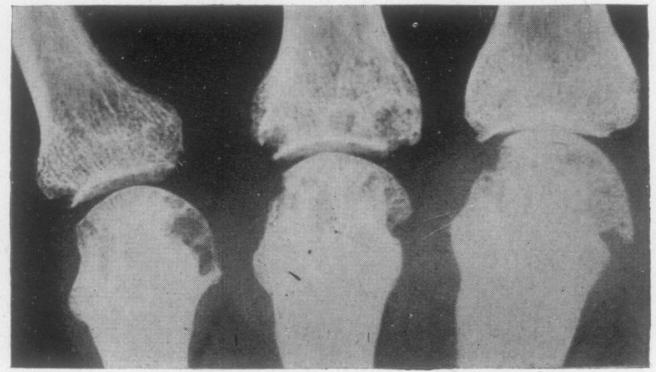

(c)

FIG. 3.-Changes during quiescence of the local joint involvement in rheumatoid arthritis. (a) Marked erosion of one joint and early local osteoporosis of the cortex in another. (b) Same case one year later, showing repair and buttressing, with cystic enclosure in the eroded joint, while erosion and loss of cartilage had proceeded in the others. (c) Three joints, deformed by rheumatoid arthritis, in the stage of local quiescence which simulates gout. (Male, 47 years, corrected suspension stability $61 \%$, plasma uric acid 4.4 mg. per 100 c.cm.; muscle section, rheumatoid arthritis history, ten years.) 


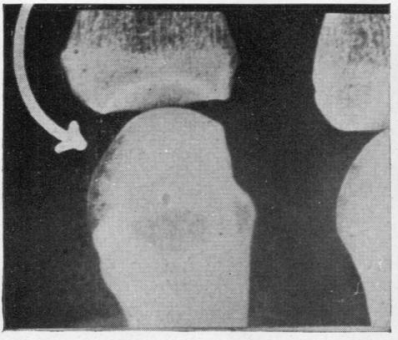

(a)

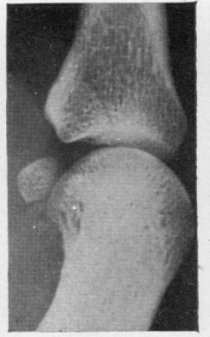

(b)

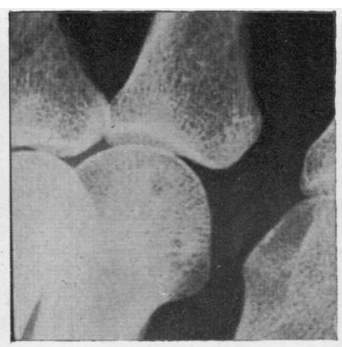

(c)

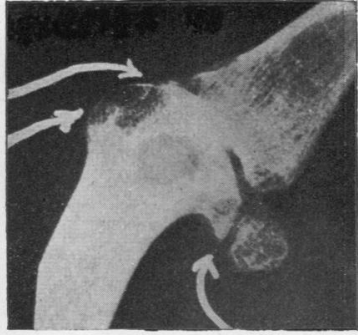

(d)

FIG. 4.-Examples of changes of gouty type from standard radiographs of the hands. (a) Zone of local translucency under the articular cortex. (b) Local translucency at the articular margin. (Plasma uric acid, $8 \mathrm{mg}$. per $100 \mathrm{c.cm}$.) (c) Chiselled-out trabeculae in small endosteal tophus. (The presence of sclerosis from osteoblastic activity indicates inactivity of the biurate deposit and commencement of the walling-in process.) (Woman, aged 53 years; corrected suspension stability $97 \%$.) (d) Subarticular tophus showing articular cortex of normal density projecting over the translucent area. (Male, 53 years; corrected suspension stability $70 \%$; plasma uric acid $8 \mathrm{mg}$. per $100 \mathrm{c.cm}$. ; history, nine years.)

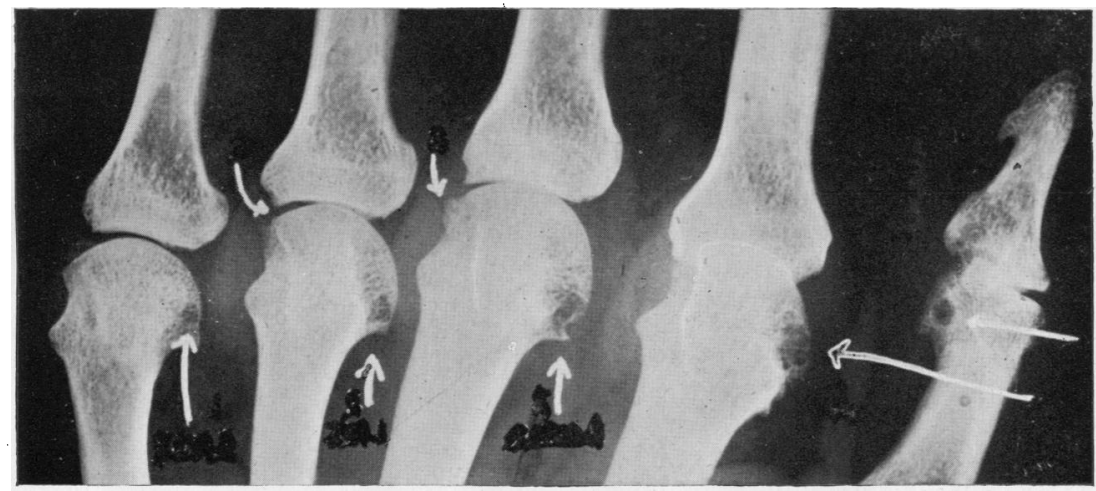

FIG. 5.-Multiple tophi showing examples of chiselled-out trabeculae, a larger tophus with crenated outline, a walled-in tophus or cyst, destruction of cartilage, and osteophytic formation. (Woman, corrected suspension stability $78 \%$ to $95 \%$; blood uric acid 2 to $4.5 \mathrm{mg}$. per $100 \mathrm{c.cm}$. of blood ; history of remissions.)

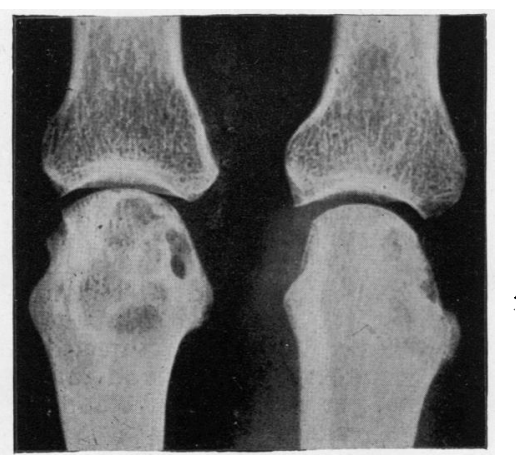

FIG. 6.- Honeycombed appearance in one bone, and multiple small tophi in another. (Male; corrected suspension stability $85 \%$; plasma uric acid $6.1 \mathrm{mg}$. per $100 \mathrm{c.cm}$. ; history, four years.) 


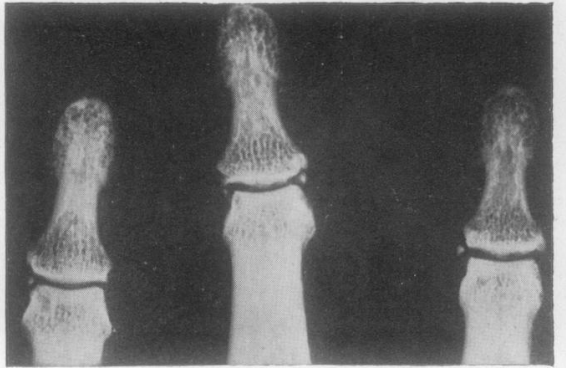

FIG. 7.-Osteo-arthritis, showing ossicles in the region of the capsule of the terminal joints of the fingers. (Corrected suspension stability $89 \%$; history, seven years.)

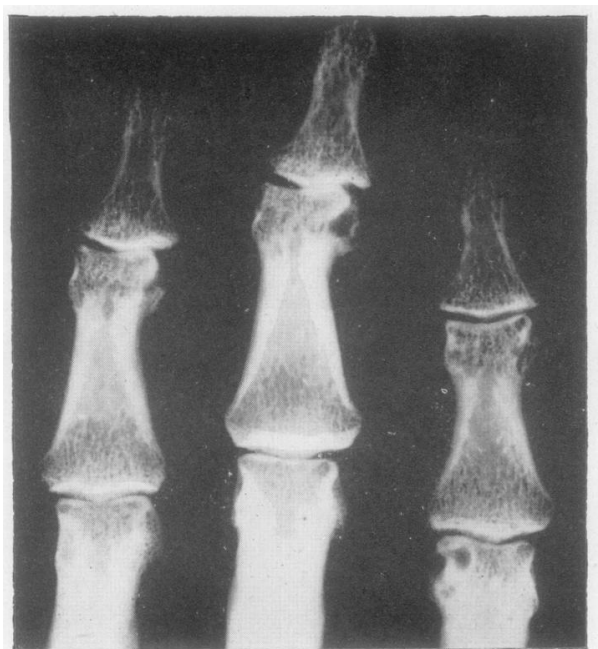

FIG. 9.-Pseudo-cystic changes in osteoarthritis simulating gout. (Male, 51 years; corrected suspension stability $83 \%$; plasma uric acid $4.4 \mathrm{mg}$. per 100 c.cm. ; history, three years.)

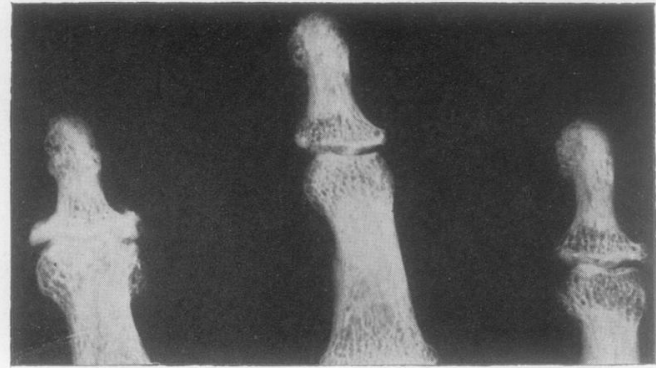

FIG. 8.-Example of Heberden's node, with true hypertrophy at the base of a terminal phalanx, together with loss of cartilage, osteosclerosis, and pitting of the articular surface. (Corrected suspension stability $88 \%$; plasma uric acid, $5 \mathrm{mg}$. per $100 \mathrm{c.cm}$.)

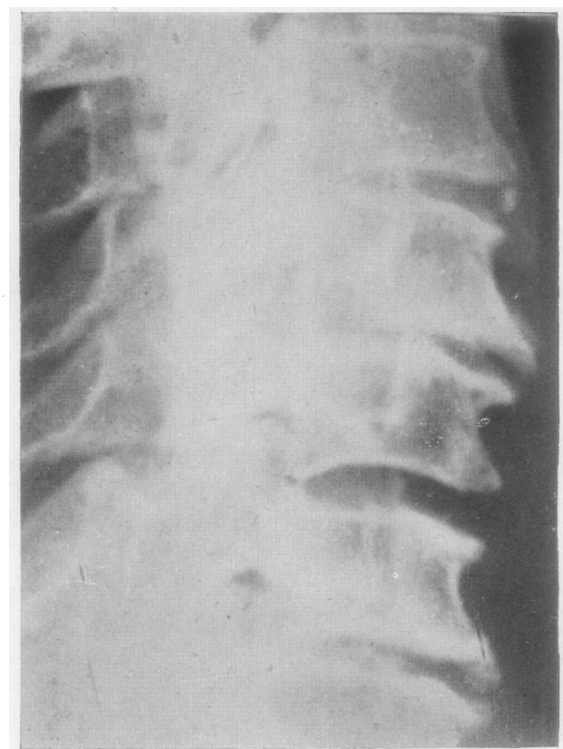

FIG. 10.-Osteo-arthritis in cervical spine, showing diminution of cartilage and osteosclerosis, with lipping in the plane of the joint. An ossicle in the region of the capsular ligament is also demonstrated. (Male, 68 years; corrected suspension stability $67 \%$; blood uric acid $4.4 \mathrm{mg}$. per $100 \mathrm{c.cm}$. of blood; history, two years.) 


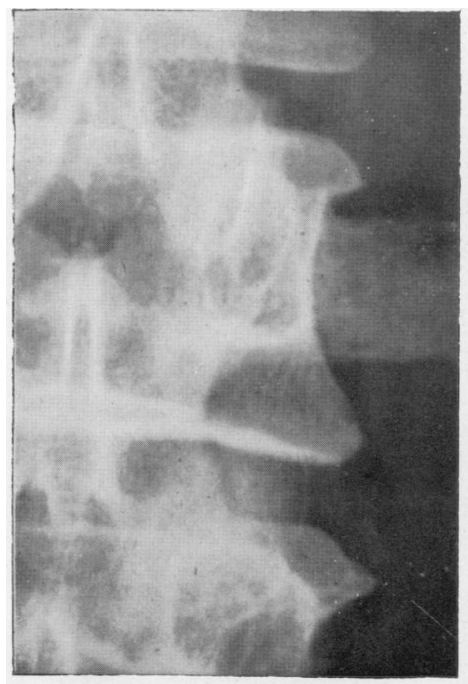

(a)

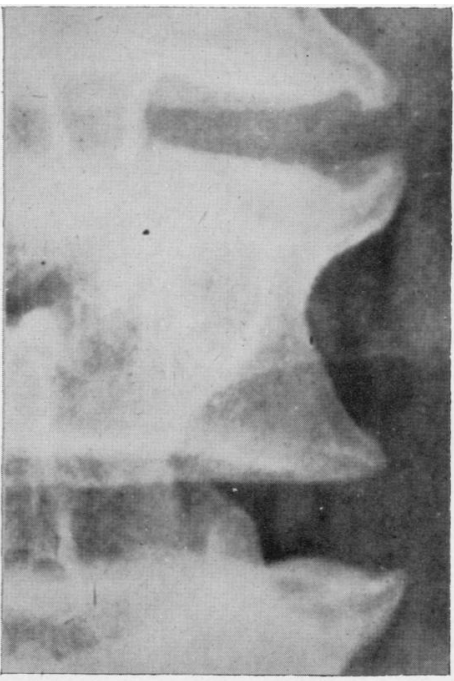

(b)

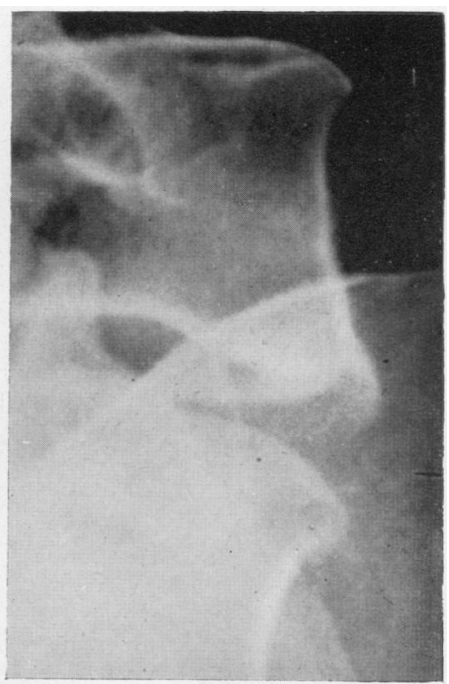

(c)

FIG. 11.-Osteophytes due to strain of the capsular ligaments without loss of articular cartilage. (a) Origin of lipping shown in the region of capsular attachments close to the articular margin. (b) Osteophytes following the line of the capsular ligaments and forming incomplete osseous bridging across the joint. (Male, 69 years; corrected suspension stability $86 \%$; blood uric acid, $3.2 \mathrm{mg}$. per $100 \mathrm{c.cm}$. of blood ; history, one year.) (c) The fringe character of these osteophytes is demonstrated in this radiograph. Shadowing is usually reproduced only where the thin fringe is in the line of the rays at the outer margins. (Female, 46 years; corrected suspension stability $89 \%$; history, two years' sciatica.)

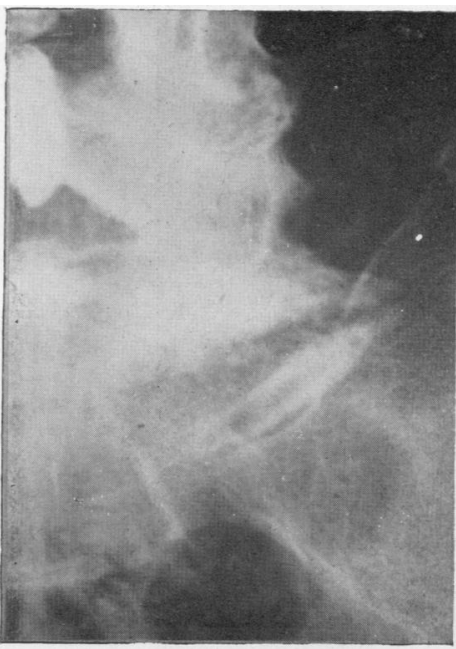

Fig. 12.-Osteophytes extending outwards in the plane of the joint in compensatory fashion, with associated loss of articular cartilage and osteosclerosis. (Woman, aged 63 years; corrected suspension stability $85 \%$; blood uric acid, $1.8 \mathrm{mg}$. per $100 \mathrm{c.cm}$. of blood ; history, one year.)

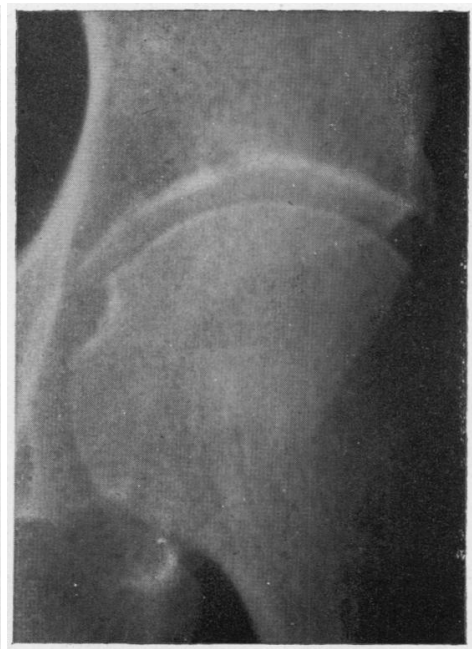

FIG. 13.-Pseudo-cystic formation in the main weight-bearing area of the acetabulum without associated loss of articular cartilage. (Woman, aged 63 years ; corrected suspension stability $85 \%$ blood uric acid, $1.8 \mathrm{mg}$. per 100 c.cm. of blood; history, one year.

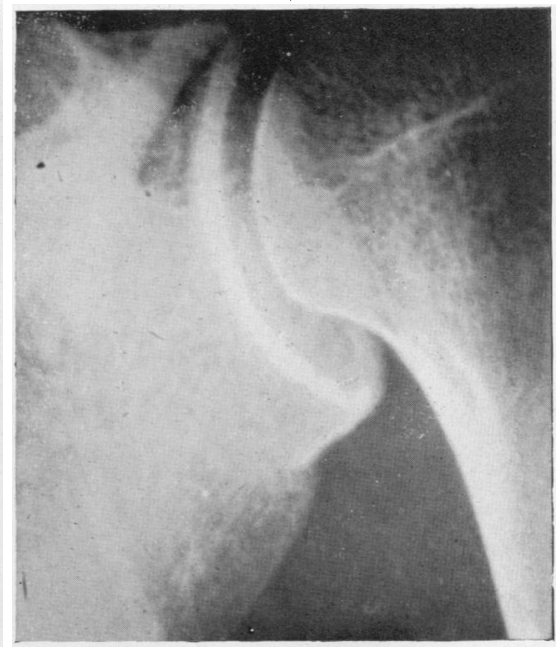

FIG. 14.-Calcification in labrum glenoidale of the shoulder joint, where osteoarthritic changes are usually less marked than in the hips and knees. 

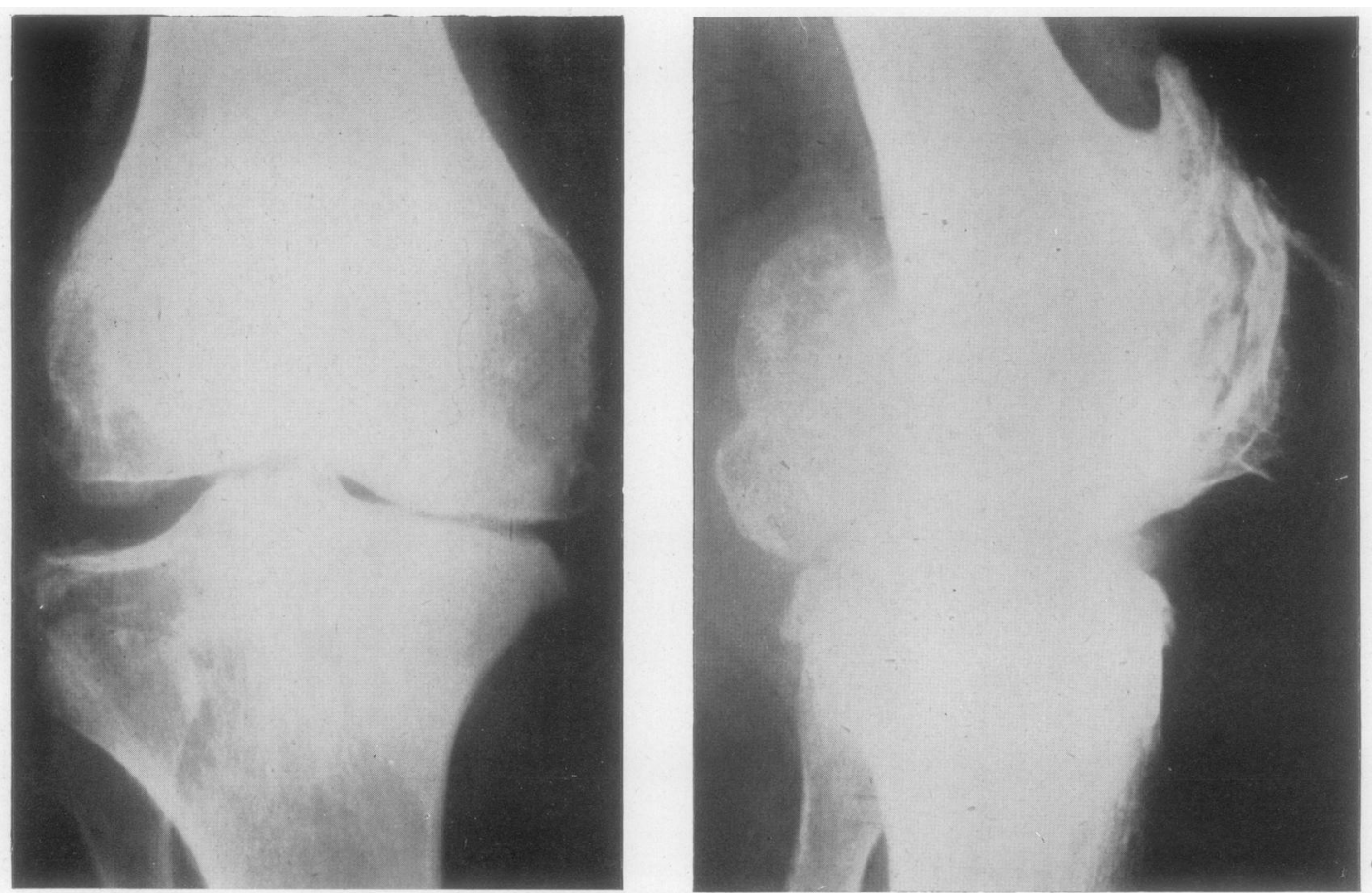

FIG. 15.-Marked osteo-arthritis in the knee joint showing (left) uneven loss of cartilage ; and (right) gross osteophytic formation of organized type. (Woman, aged 54 years ; corrected suspension stability $78 \%$; history of pain after menopause, ten years.)

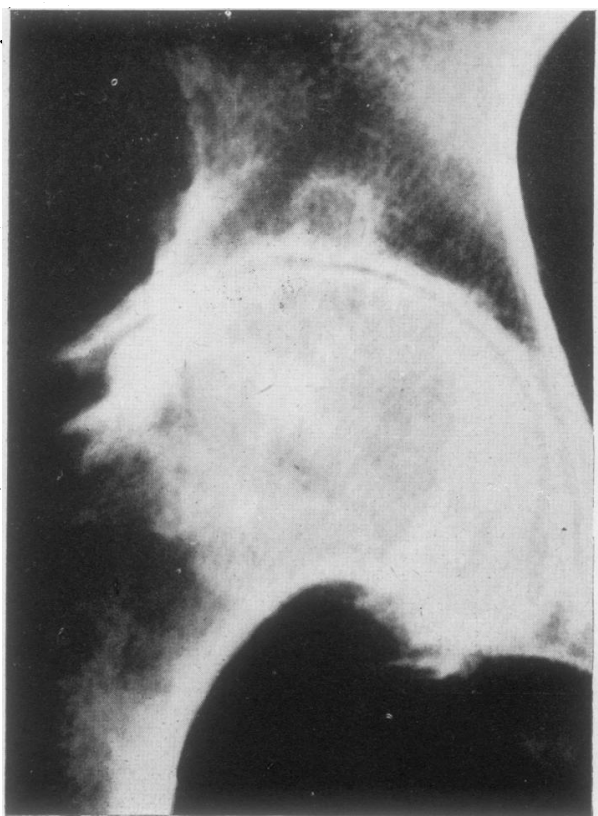

FIG. 16.-Osteo-arthritic changes in hip joint, of secondary type with spiky lipping and uniform loss of cartilage. (Corrected suspension stability $67 \%$; with thirteen years' history of rheumatoid arthritis.)

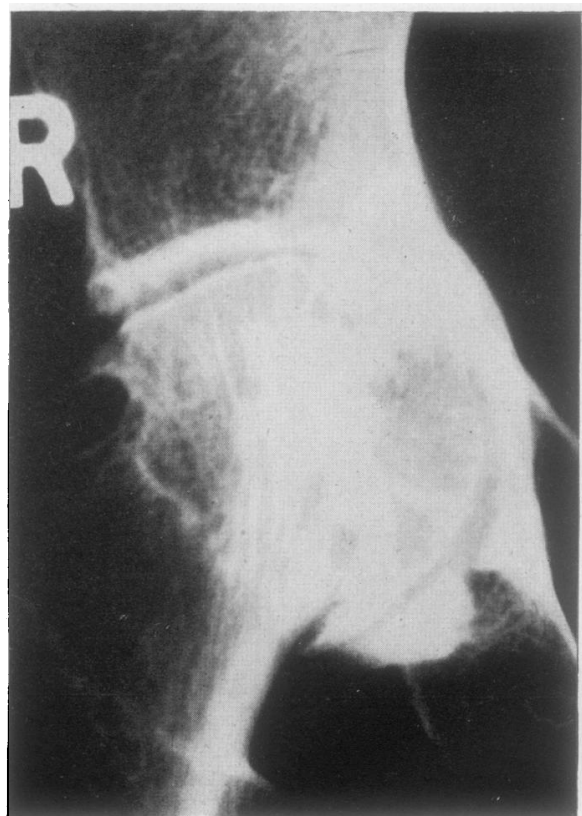

FIG. 17.-Osteo-arthritis in the hip joint, secondary to protusio-acetabuli. (Woman, aged 56 years; corrected suspension stability $86 \%$; history, two years.) 


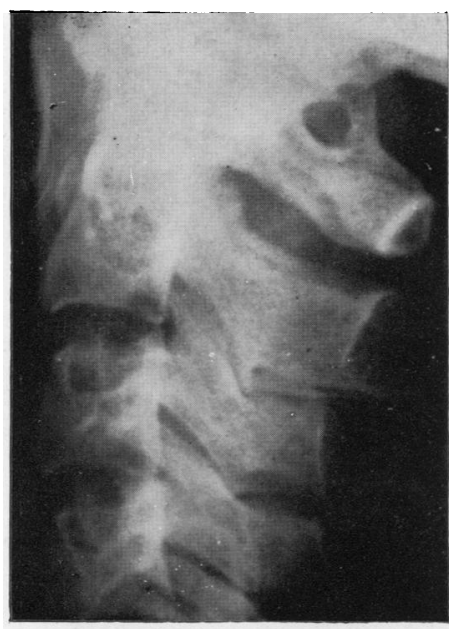

(a)

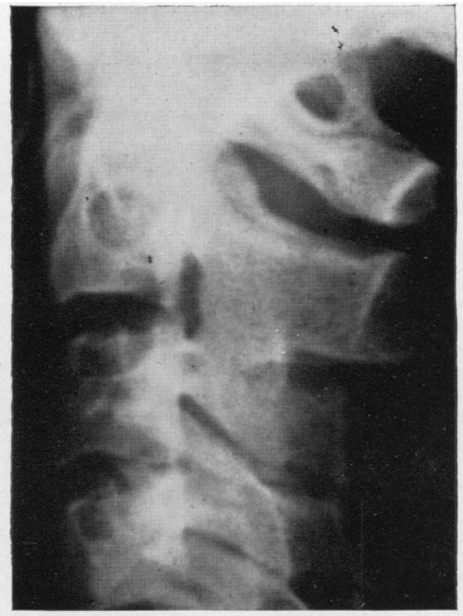

(b)

FIG. 18.-Case of rheumatoid arthritis with involvement of spine. (Corrected suspension stability $81 \%$; blood uric acid $4.4 \mathrm{mg}$. per 100 c.cm. of blood ; history, 15 years.) (a) Local changes in the interarticular joint between the second and third cervical vertebrae. (b) The same case, showing ankylosis in the affected joint four years later.

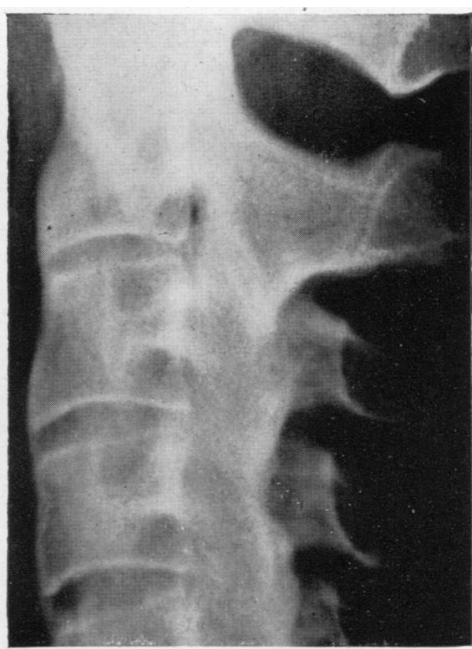

FIG. 19.-Multiple joint involvement in the cervical spine due to ankylosing spondylitis. (Man, aged 32 years ; corrected suspension stability $57 \%$; blood uric acid $3.8 \mathrm{mg}$. per $100 \mathrm{c.cm}$. of blood.)

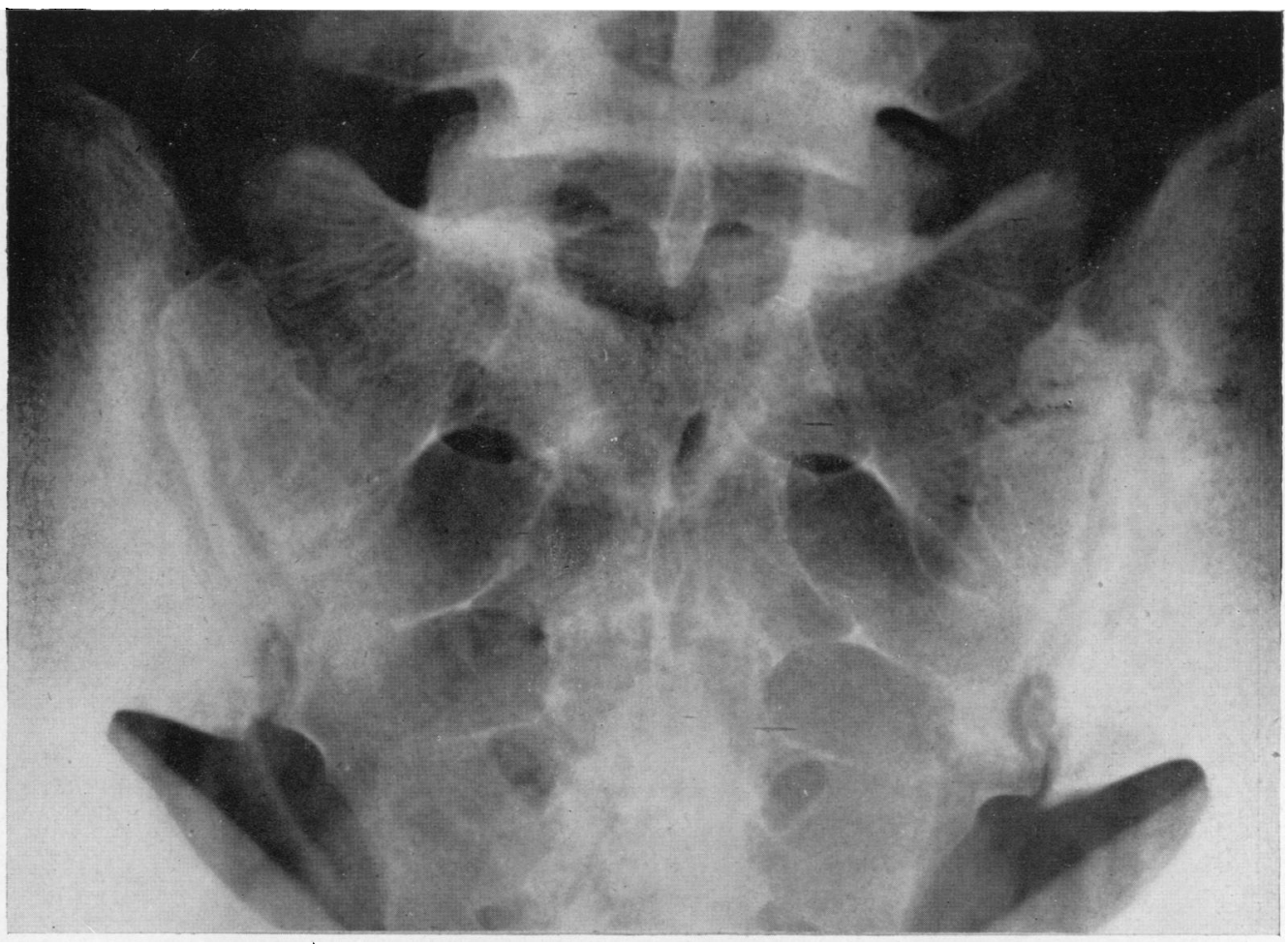

FIG. 20.- "Mobilization of calcium" in the subarticular zone of the sacro-iliac joints, offering presumptive evidence of ankylosing spondylitis. In addition to this, the cortical outline of the upper portion of the left ala of the sacrum has disappeared. (Woman, aged 31 years; corrected suspension stability $68 \%$; history, four years.) 

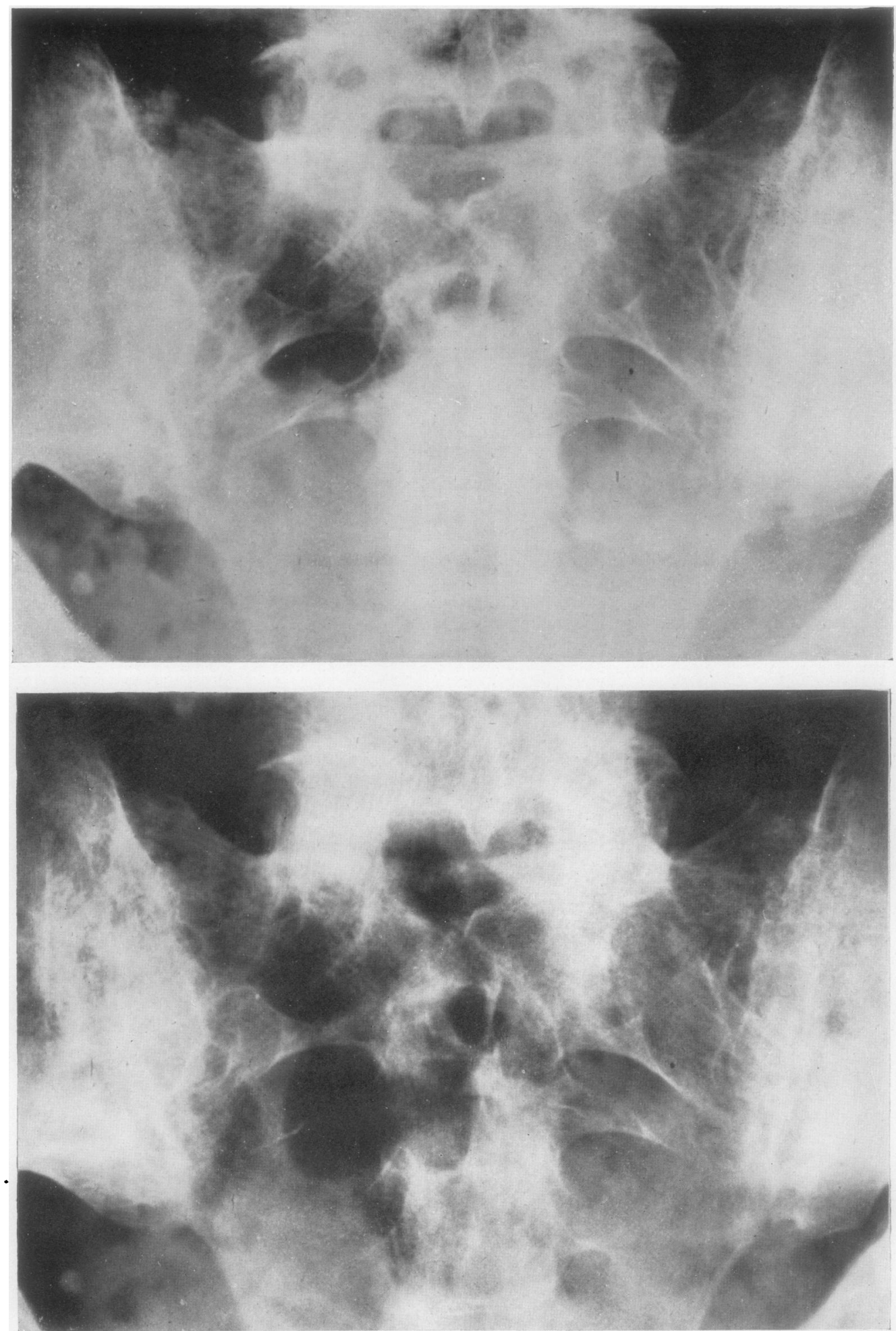

Fig. 21.-Above, zonal sclerosis, similar to Fig. 20, in a frank case of ankylosing spondylitis. Below, the same case nine months later, showing increase of the osteoporosis in the sacrum and iliac bones, with diminution of calcium in the opaque subarticular zones. (Man, aged 36 years ; corrected suspension stability $66 \%$; plasma uric acid $6.1 \mathrm{mg}$. per $100 \mathrm{c.cm}$. ; history, two years.) 


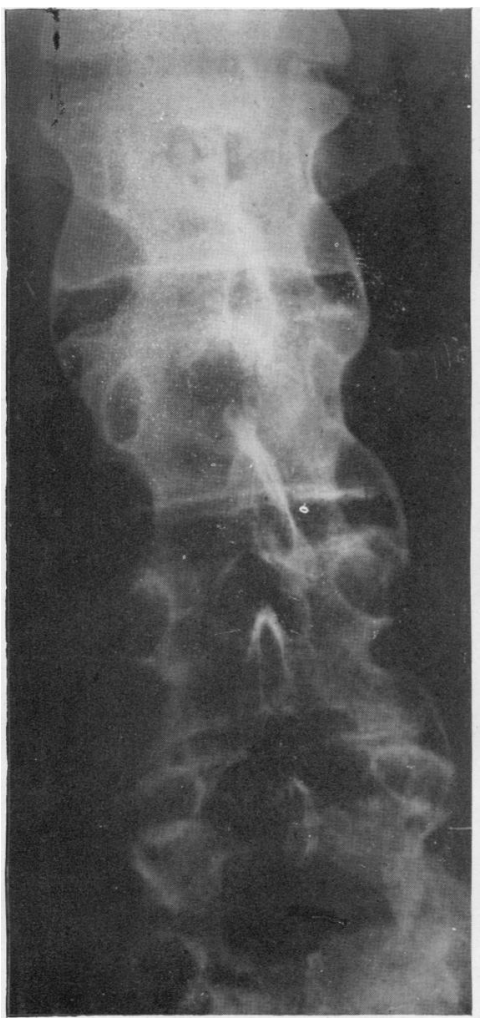

Fig. 22.

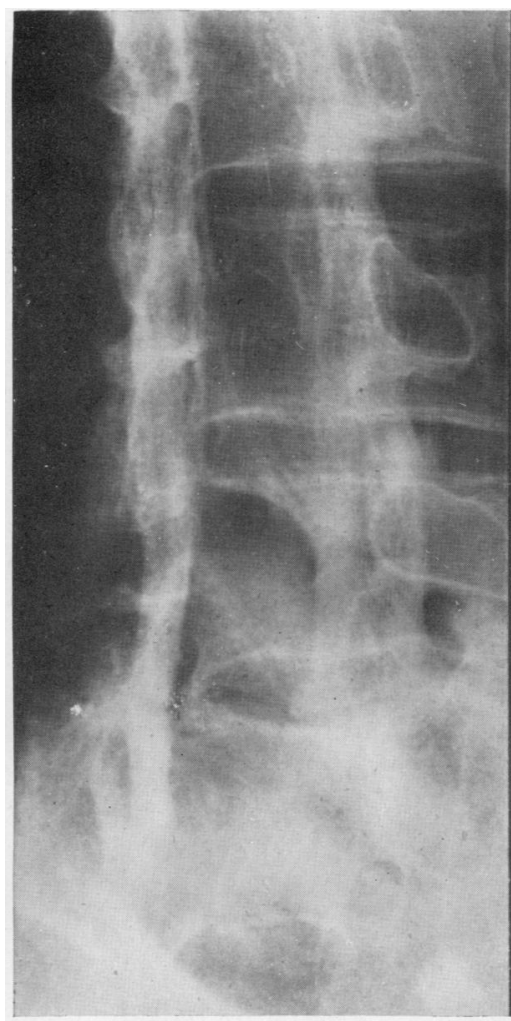

FIG. 23.

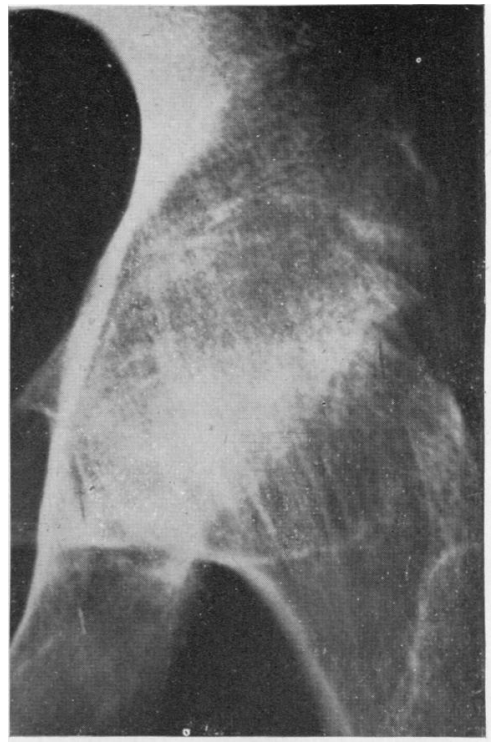

Fig. 24.

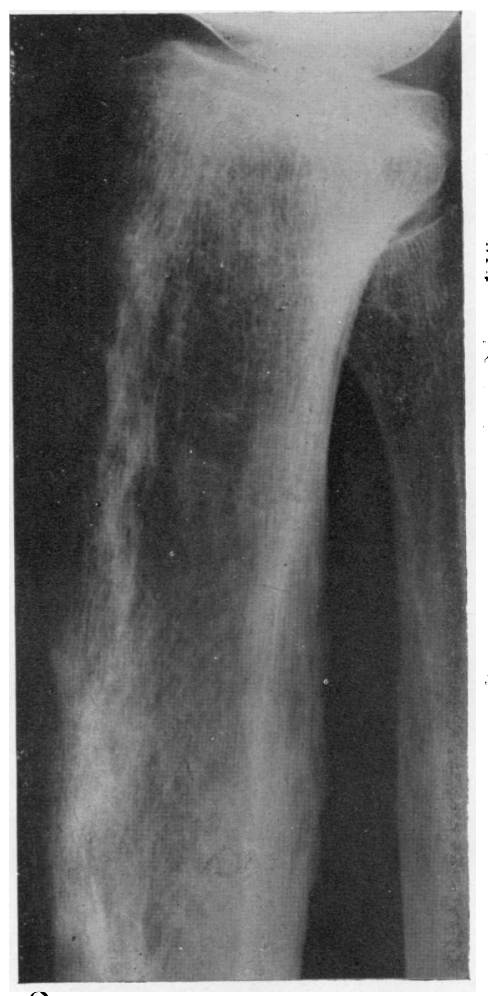

Fig. 25. 